\title{
Review Article \\ Roles of NUCKS1 in Diseases: Susceptibility, Potential Biomarker, and Regulatory Mechanisms
}

\author{
Pengru Huang, Yujie Cai, Bin Zhao $(D$, and Lili Cui \\ Guangdong Key Laboratory of Age-Related Cardiac and Cerebral Diseases, Affiliated Hospital of Guangdong Medical University, \\ Zhanjiang, Guangdong, China
}

Correspondence should be addressed to Bin Zhao; binzhaoe@163.com and Lili Cui; cuilili@gdmu.edu.cn

Received 15 September 2017; Accepted 31 December 2017; Published 29 January 2018

Academic Editor: Terri L. Young

Copyright (C) 2018 Pengru Huang et al. This is an open access article distributed under the Creative Commons Attribution License, which permits unrestricted use, distribution, and reproduction in any medium, provided the original work is properly cited.

\begin{abstract}
Nuclear casein kinase and cyclin-dependent kinase substrate 1 (NUCKS1) is a $27 \mathrm{kD}$ chromosomal, highly conserved, and vertebrate-specific protein. NUCKS1 gene encodes a nuclear protein and the conserved regions of NUCKS1 contain several consensus phosphorylation sites for casein kinase II (CK2) and cyclin-dependent kinases (Cdk) and a basic DNA-binding domain. NUCKS1 is similar to the high mobility group (HMG) family which dominates chromatin remodeling and regulates gene transcription. Meanwhile, NUCKS1 is a RAD51 associated protein 1 (RAD51AP1) paralog that is significant for homologous recombination (HR) and genome stability and also a transcriptional regulator of the insulin signaling components. NUCKS1 plays an important role in DNA damage response and metabolism, participates in inflammatory immune response, and correlates with microRNA. Although there is still not enough functional information on NUCKS1, evidences suggest that NUCKS1 can be used as the biomarker of several cancers. This review summarizes the latest research on NUCKS1 about its susceptibility in diseases, expression levels, and regulatory mechanisms as well as the possible functions in reference to diseases.
\end{abstract}

\section{Introduction}

Nuclear casein kinase and cyclin-dependent kinase substrate 1 (NUCKS1), which is located on human chromosome 1q32.1 [1], is a member of the high mobility group (HMG) family [2]; NUCKS1 is widespread in vertebrates and is expressed ubiquitously by almost all human cell types [24]. NUCKS1 plays a significant role in modulating chromatin structure [1] and regulates cellular events such as replication, transcription, and chromatin condensation [2]. Remarkably, in contrast to HMG, NUCKS1 is highly phosphorylated at multiple sites $[5,6]$. NUCKS1 can be phosphorylated by kinases, such as casein kinase II (CK2) and cyclindependent kinase (Cdk) and DNA-activated protein kinase. Notably, NUCKS1 can also be phosphorylated in all phases of the cell cycle and exhibit the mitosis-specific phosphorylation of threonine residues [4,7], which is implicated in cell growth and proliferation as well as DNA repair [710]. Moreover, posttranslational modifications of NUCKS1, which include acetylation, methylation, ubiquitylation, and formylation, mainly occur in interphase [6]. In addition, in vitro experiments have indicated that NUCKS1 can act as a substrate for second messenger-activated kinases [11]. The aforementioned functions of NUCKS1 contribute to the susceptibility, occurrence, and development of several cancers and other diseases and suggest that NUCKS1 could be a potent marker for such diseases [12]. An understanding of additional potential functions of NUCKS1 may provide new insight into novel therapeutic strategies to address the development of these diseases. In this article, we focus on new evidence regarding the associations between NUCKS1 and susceptibility to diseases; NUCKS1 expression levels in diseases; and regulatory mechanisms involving NUCKS1 in the context of diseases.

\section{Genetic Susceptibilities Associated with NUCKS1}

Increasing evidence support the existence of complex genetic contributions to disease development [13-20]. Genomewide association studies (GWAS) have shed light on the 


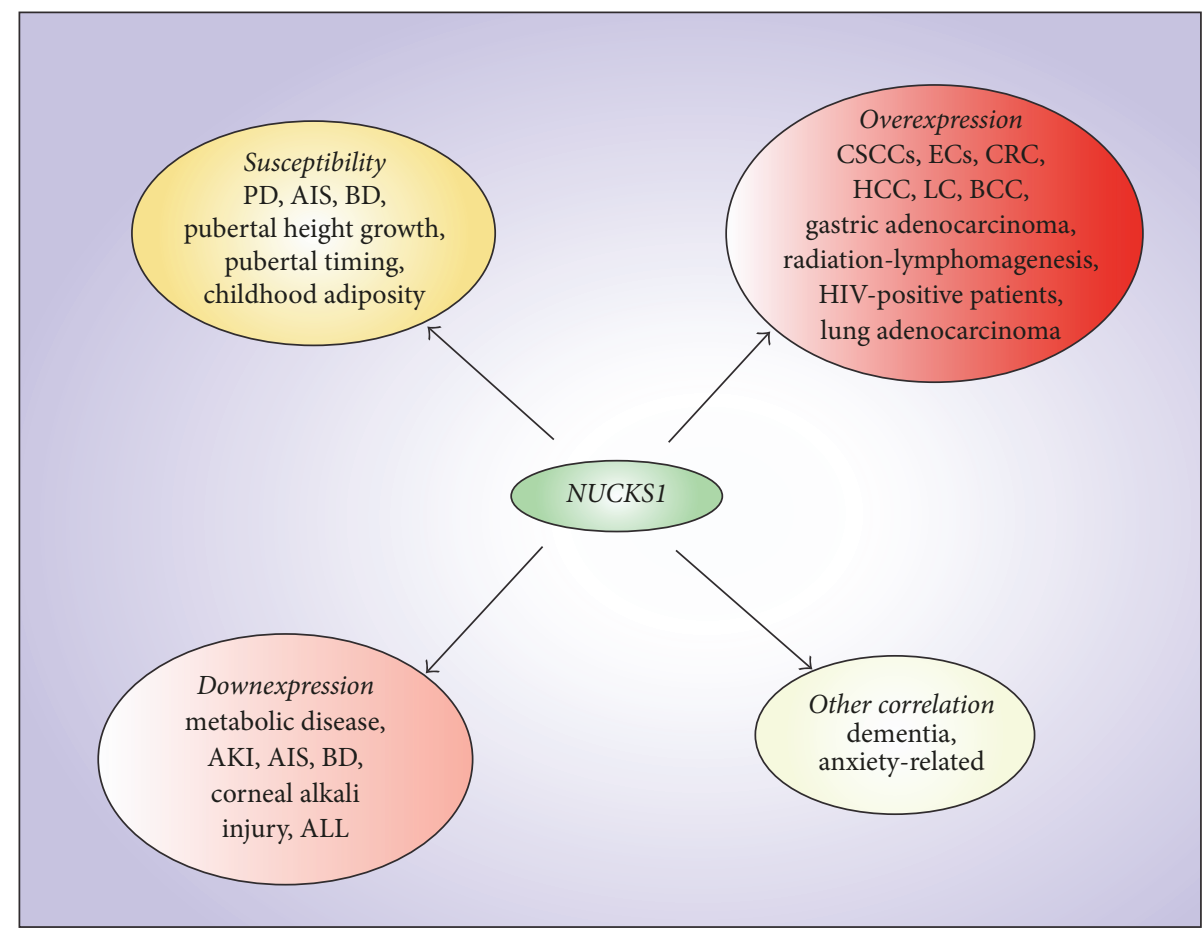

FIgURE 1: The association between NUCKS1 and diseases/metabolic process. NUCKS1 is one of susceptible genes in Parkinson disease (PD), adolescent idiopathic scoliosis (AIS), bipolar disorder (BD), and so on. NUCKS1 has overexpression in many tumours, such as cervical squamous cell carcinomas (CSCCs), endometrial cancers (ECs), colorectal cancer (CRC), hepatocellular carcinoma (HCC), lung cancer (LC), and basal cell carcinoma (BCC) and in human immunodeficiency virus (HIV) positive patients in in vivo studies. NUCKS1 also has overexpression in lung adenocarcinoma according to in vitro study. But NUCKS1 has downexpression in acute kidney injury (AKI), AIS, BD, and so on, in in vivo studies, as well as in acute lymphoblastic leukemia (ALL) which is in vitro study. Besides, NUCKS1 has correlation with dementia and anxiety.

genetic basis of disease, leading to the identification and replication of risk loci that fit the common disease-common variant hypothesis [13-16, 19]. The NUCKS1 gene, which contains thousands of related single-nucleotide polymorphisms (SNPs), has been reported to be potentially associated with several diseases and with the growth and development of adolescents. GWAS have identified NUCKS1 as one of five transcripts of the PARK16 locus on 1q32, which is a susceptibility locus associated with Parkinson disease (PD) [21]. Furthermore, transcript levels of NUCKS1 (including rs947211 and rs823114) have been shown to be strongly associated with PD in a Japanese population [22]. However, no significant associations between rs823114 of NUCKS1 and PD have been observed in Ashkenazi Jewish [23, 24], Chinese [25], and Scandinavian [26] populations. In addition, rs823128 of NUCKS1 is associated with PD at or close to a genome-wide significance level in Asians but not Caucasians (CEU) [27]. However, in other data, there was strong linkage disequilibrium (LD) for rs823128 in NUCKS1 with five SNPs (rs823123, rs823135, rs823136, and rs823142 in RAB7L1 and rs1620334 in NUCKS1) in all ethnic groups but with rs823092 in NUCKS1 only in Asian groups [28]. Moreover, RAB7L1/NUCKS1 has candidate genetic variants that may be associated with sporadic PD in Han Chinese subjects. Furthermore, for RAB7L1/NUCKS1 rs823118, subjects with the CC or CT genotype had lower risks of PD than subjects with the TT genotype [29]. NUCKS1 (rs4880445) is also a potential susceptibility gene for bipolar disorder (BD) that has been identified in youth at high risk for $B D$ via a combined transcriptome and methylome analysis [30]. Remarkably, a recent GWAS showed that a menarche genomic locus, rs951366 of NUCKS1, is highly enriched for variants that more generally regulate pubertal timing [31]. In addition, rs951366 of NUCKS1 has been reported to be a susceptibility gene of adolescent idiopathic scoliosis (AIS). Moreover, patients with a $\mathrm{T}$ allele for rs951366 are more vulnerable to AIS as well as late onset of menarche [32]. Intriguingly, in a longitudinal study, rs823094 of NUCKS1 was found to be associated with pubertal height gain [33]. As noted, NUCKS1 has been identified as a potential susceptibility gene for $\mathrm{PD}, \mathrm{BD}$, pubertal height gain, pubertal timing, childhood adiposity, and AIS (Figure 1).

\section{Levels of NUCKS1 in Diseases}

NUCKS1 is ubiquitously expressed in all mammalian tissues $[3,4]$ and has been confirmed to be overexpressed in many cancers, especially malignant neoplasms. Therefore, NUCKS1 can be used as a marker for various cancers [12, 34-46]. In in vivo studies, a high level of NUCKS1 may be associated with tumor progression and recurrence in cervical squamous 
cell carcinomas (CSCCs) [34]. In addition, overexpression of NUCKS1 is strongly correlated with various characteristics of endometrial cancers (ECs), including FIGO stage, histologic grade, lymphovascular space involvement, lymph node metastasis, and recurrence, although NUCKS1 expression is not significantly correlated with other clinicopathologic factors [35]. Meanwhile, NUCKS1 has been identified as a candidate gene involved in distant metastasis in colorectal cancer (CRC) and gastric adenocarcinoma. However, there are no strong relationships between NUCKS1 and other clinical variables (such as gender and age) $[36,37]$. Moreover, combined overexpression of NUCKS1 and Ki-67 (a wellknown proliferation marker [38]) has been identified as an independent prognostic factor for both disease-free survival and overall survival in gastric adenocarcinoma patients [37]. In skin tumors, high expression of NUCKS1 in the nuclei of squamous cell carcinoma (SCC) and basal cell carcinoma (BCC) cells is more common than Ki67 expression. NUCKS1 expression has been found to be much lower in benign keratoacanthoma (KA) than in malignant tumors [39]. In breast carcinoma, NUCKS1 has exhibited higher expression than other investigated markers (including Ki67, estrogen receptor, progesterone receptor, human epidermal growth factor receptor 2 , and cytokeratin 5/6) $[40,41]$. Additionally, NUCKS1 is also highly expressed in breast cancer with obesity [42]; these findings are consistent with results obtained in a previous study [43]. NUCKS1 is a novel immunohistochemical marker for the early detection of hepatocellular carcinoma (HCC) [44]. Furthermore, NUCKS1 is elevated in human lung cancer (LC) tissues; this elevation is inversely correlated with miR-137 expression levels [45]. Moreover, NUCKS1 is one of the most significant transcription factors in LC and is predicted to be a therapeutic transcription factor [46]. Besides, after $4 \mathrm{~Gy}$ of total-body X-ray irradiation, Trp53+/NUCKS1+/- mice developed tumors more rapidly than Trp53+/- mice [47]. In addition to cancer, NUCKS1 is highly expressed in tissues from human immunodeficiency virus(HIV-) positive patients [48]. Intriguingly, NUCKS1 expression is elevated during the initial stages of embryonic development and then gradually decreases until birth in all tissues except for nervous tissue and muscle fibers [3]. Similarly, in in vitro studies, the results were also consistent with in vivo studies. NUCKS1 expression is increased in a highly invasive lung adenocarcinoma cell line [49]. Remarkably, NUCKS1 is critical for tumor suppression and the DNA damage response [50]. Taken together, the aforementioned findings indicate that NUCKS1 is highly expressed in many cancers and in HIV-positive patients and can be used as a marker for cancers. Furthermore, NUCKS1 is associated with the depth of invasion and tumor node metastasis classification, but there are no significant correlations between NUCKS1 expression and gender or age. In summary, further studies are needed to elucidate the mechanism by which NUCKS1 leads to oncogenesis. However, in contrast to the cancers mentioned above, in adult T-cell leukemia-lymphoma (ATLL), NUCKS1 expression has been found to be lower than the average NUCKS1 expression across all specimens [51]. In addition, NUCKS1 is reduced in acute kidney injury (AKI) [52], and the inhibition of NUCKS1 plays a role in cytokine modulation and facilitates corneal recovery following alkali burn [53]. Intriguingly, NUCKS1 knockout (NKO) mice [54] and hypothalamus-specific deletion of NUCKS1 (HNKO) mice [55] exhibit decreased insulin signaling, increased body weight/fat mass, impaired glucose tolerance, and reduced insulin sensitivity. Moreover, NUCKS1 has been shown to exhibit low expression in a mood disorder group relative to healthy controls (HCs) [56]. Recently, markedly lower NUCKS1 expression has been found in subjects with AIS compared with controls, particularly for patients with the TT genotype [32]. In addition to the in vivo studies mentioned above, the following in vitro studies showed the same results; in childhood acute lymphoblastic leukemia (ALL), compared with NUCKS1 expression in Reh cells overexpressing a scrambled control miRNA, NUCKS1 is downregulated in Reh cells overexpressing miR-125b, miR-99a, and/or miR100 [57]. Notably, NUCKS1 knockdown sensitizes cells to mitomycin $\mathrm{C}$ and $\mathrm{X}$-rays and promotes chromatid-type aberrations [50]. Overall, NUCKS1 is downregulated in lymphoma, acute inflammatory disease, metabolic diseases, mood disorders, and AIS (Figure 1).

\section{Functions of NUCKS1 in Diseases}

4.1. Metabolism. Notably, in in vivo studies, NUCKS1 has been found to be a transcriptional regulator of insulin signaling components, and genome-wide ChIP-seq has identified metabolism and insulin signaling as NUCKS1 targets [54]. Specifically, NUCKS1 is a physiological regulator of energy homeostasis and glucose metabolism that functions by regulating chromatin accessibility and the recruitment of RNA polymerase II (poly II) to promoters of insulin receptor (IR) and other insulin pathway modulators [54]. In addition, NUCKS1 has other targets that regulate insulin signaling, and it is common for transcription factors such as nuclear factor $\kappa \mathrm{B}(\mathrm{NF}-\kappa \mathrm{B})$ or Myc to regulate multiple members of a signaling cascade to control physiological effects [58-61]. Furthermore, NUCKS1 can bind the promoter regions of a few genes in several pathways [54]. Hypothalamic NUCKS1 plays an essential role in regulating in vivo peripheral glucose homoeostasis and insulin signaling [55] (Figure 2).

4.2. Inflammatory Immune Response. In vivo studies results have suggested that the inhibition of NUCKS1 plays a role in cytokine modulation and facilitates corneal recovery [53]. Such inhibition decreases the angiogenic response and angiogenic vascular endothelial growth factor (VEGF) but increases antiangiogenic factors (such as pigment epitheliumderived factor (PEDF)) following in vivo alkali injury. Moreover, NUCKS1 regulates NF- $\kappa \mathrm{B}$ activation. Following lipopolysaccharide- (LPS-) induced NF- $\kappa \mathrm{B}$ activation, NUCKS1 knockout corneal epithelial cells showed reduced expression of phosphorylated $\mathrm{I} \kappa \mathrm{B}(\mathrm{P} \mathrm{I} \kappa \mathrm{B})$, interleukins (including IL6), IP10, and tumor necrosis factor $\alpha$ (TNF $\alpha)$. Given the aforementioned data, NUCKS1 regulates NF- $\kappa \mathrm{B}$, the expression of particular NF- $\kappa \mathrm{B}$-mediated cytokines, and the phosphorylation of specific proteins critical to the NF- $\kappa \mathrm{B}$ signaling pathway in ocular epithelial cells [53]. Remarkably, in in vitro study, NUCKS1 has been shown to increase 


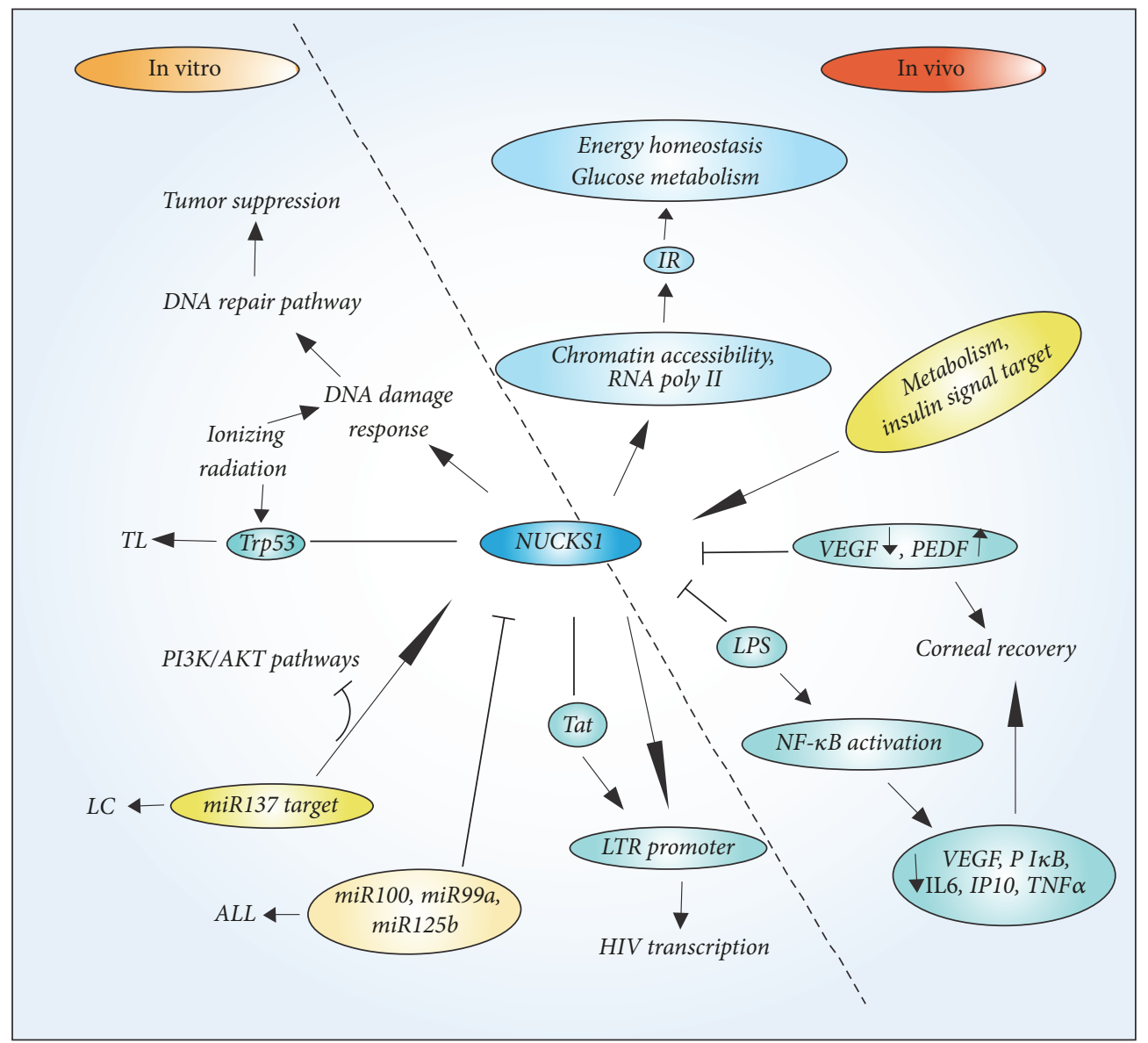

FIGURE 2: The metabolic pathway of NUCKS1 in physiological and pathological process. In in vivo studies, NUCKS1 plays the important roles in other metabolic diseases, especially involving in regulating insulin metabolism. NUCKS1 has correlation with the inflammatory immune diseases via involving in up-and-down certain cytokines and activating some pathways. In in vitro studies, NUCKS1 has connection with miRNA, but the expression level of them is inversely. Meanwhile, NUCKS1 plays significant roles in DNA damage response and participates in DNA repair pathway.

Tat-mediated transcriptional activity of the HIV-1 long terminal repeat (LTR) in an NF- $\kappa$ B-independent manner [48] (Figure 2).

4.3. NUCK1 and MicroRNA. NUCKS1 directly interacts with miR-92a-3p and miR-29b-3p in BD patients [62]. Meanwhile, in in vitro studies, NUCKS1 is downregulated upon enforced expression of miR-125b in combination with miR-99a and/or miR-100 compared with scrambled control-miR in ALL [57]. In addition, miR-137 $3^{\prime}$-UTR directly targets NUCKS1 by binding to its seed region in LC cells. Furthermore, miR-137 inhibits PI3K/AKT pathways by targeting NUCKS1 [45]. In addition, siRNA silencing of NUCKS1 significantly suppresses tumor growth. The inhibition of NUCKS1 affects changes in the expression of proteins involved in cell signaling, nucleic acid metabolism, and several microRNAs (including miR4796, miR1305, miR4762, and miR4445) [44] (Figure 2).

4.4. DNA Damage Repair. NUCKS1 resembles other members of the HMG family, which dominate chromatin remodeling and regulate gene transcription. It has been reported that Trp53+/- NUCKS1+/- mice frequently succumbed to CD4- CD8- thymic lymphomas (TLs). In the context of Trp53 deficiency, wild-type levels of NUCKS1 are required to suppress radiation-induced TLs; this suppression likely involves the role of the NUCKS1 protein in the DNA damage response [47]. Recently, in in vitro studies, NUCKS1 is a novel RAD51 associated protein 1 (RAD51AP1) paralog that is important for homologous recombination (HR) and genome stability [50]. Moreover, NUCKS1 is a chromatinassociated protein with a role in the DNA damage response and in HR, a DNA repair pathway critical for tumor suppression [50]. However, at the core of the DNA damage signaling apparatus is a pair of related protein kinases, ataxia telangiectasia mutated (ATM), and ATM and Rad3-related (ATR) that are activated by DNA damage [63]. Notably, NUCKS1 is a substrate of either ATM or ATR following exposure to ionizing radiation [64]. Intriguingly, NUCKS1, which has been confirmed to be associated with DNA replication, is highly expressed in S-phase cells during DNA damage repair following ionizing radiation [50] (Figure 2). 


\section{Conclusions and Perspectives}

GWAS have clarified that NUCKS1 is a susceptibility gene for various diseases. Furthermore, GWAS have also shown that a single disease can be associated with multiple SNPs of NUCKS1. However, NUCKS1 has diverse expression in different races, even when the same SNP of NUCKS1 and the same disease are examined. Moreover, NUCKS1 genotypes exhibit distinct expression for certain diseases. The exact roles of NUCKS1 in diseases remain obscure, although it has been reported that expression and transcription levels of NUCKS1 are significantly associated with PD $[13,22]$ and that NUCKS1 transcription and methylation are likely to play a vital role in youths with BD [30]. In addition, tumors with high NUCKS1 expression have exhibited increased invasive potential $[35,40]$. NUCKS1 may promote tumor cell proliferation, progression, and invasion [35, 36, 44, 49]. Similarly, NUCKS1 may have a role in signal transduction in cancer [44]. Furthermore, NUCKS1 could be an independent prognostic factor for cancer recurrence [34, 36]. Notably, NUCKS1 plays a vital role in mitigating replication stress in human cells. NUCKS1 expression may be upregulated as part of the activated DNA damage response network during tumorigenesis. In addition, NUCKS1 may be associated with a selective advantage during tumor initiation and development that allows early neoplastic cells to overcome replication stress [47]. However, the relationship between elevated levels of NUCKS1 and tumor progression is currently unknown, and further work is needed to clarify the roles of NUCKS1 in tumor progression. In contrast, NUCKS1 has low expression in acute inflammatory diseases. This finding may be associated with the role of NUCKS1 as a transcription factor to regulate $\mathrm{NF} \kappa \mathrm{B}$ activation and release NF $\kappa$ B-mediated cytokines [53]. Furthermore, NUCKS1 is also downregulated in metabolic diseases [54, 55]. It is highly likely that modifications in NUCKS1 could link insulin signaling and energy homeostasis to changes in myriad cellular processes [54]. Future studies directed at understanding the tissue- and stimuli-specific downstream targets of NUCKS1 may provide promising therapeutic approaches in the treatment of obesity and insulin resistance [54]. Moreover, neuron-specific depletion of NUCKS1 will provide a better understanding of metabolic phenotypes [55]. Such understanding will provide guidance for exploiting NUCKS1 as a potential target in the treatment of impaired glucose homoeostasis [55]. Similarly, NUCKS1 has been found to be decreased in a mood disorder group relative to a HC group. This observation may be correlated with transcriptional regulation by NUCKS1 via chromatin remodeling [5]. In addition, in AIS, rs951366 maps the $3^{\prime}$ untranslated region of NUCKS1, which encodes a cell cycle-related protein and plays an important role in cell proliferation and cell progression. In addition, the LD block of rs951366 maps a DNase I hypersensitivity site in multiple cell lines and might also be located in a strong enhancer region marked by several active histone methylation modifications [65]. The rs951366 locus has the potential to regulate the transcriptional activity of NUCKS1 and therefore merits additional functional analysis. Overall, the functions of NUCKS1 have remained largely unknown, and more studies are needed to reveal more details about these functions in the future.

\section{Conflicts of Interest}

The authors declare no conflicts of interest.

\section{Authors' Contributions}

Pengru Huang and Yujie Cai wrote the paper; Bin Zhao and Lili Cui designed and revised the paper.

\section{Acknowledgments}

This work was supported by funding from the National Nature Science Foundation of China (81671181 and 81771161).

\section{References}

[1] K. Grundt, I. V. Haga, V. Aleporou-Marinou, Y. Drosos, B. Wanvik, and A. C. Østvold, "Characterisation of the NUCKS gene on human chromosome 1q32.1 and the presence of a homologous gene in different species," Biochemical and Biophysical Research Communications, vol. 323, no. 3, pp. 796-801, 2004.

[2] A. C. Ostvold, J. Holtlund, and S. G. Laland, "A novel, highly phosphorylated protein, of the high-mobility group type, present in a variety of proliferating and non-proliferating mammalian cells," European Journal of Biochemistry, vol. 153, no. 3, pp. 469-475, 1985.

[3] Y. Drosos, M. Kouloukoussa, A. C. Stvold et al., "Dynamic expression of the vertebrate-specific protein Nucks during rodent embryonic development," Gene Expression Patterns, vol. 14, no. 1, pp. 19-29, 2014.

[4] A. C. Stvold, J. H. Norum, S. Mathiesen, B. Wanvik, I. Sefland, and K. Grundt, "Molecular cloning of a mammalian nuclear phosphoprotein NUCKS, which serves as a substrate for Cdk1 in vivo," European Journal of Biochemistry, vol. 268, no. 8, pp. 2430-2440, 2001.

[5] K. Grundt, L. Skjeldal, H. W. Anthonsen, T. Skauge, H. S. Huitfeldt, and A. C. Østvold, "A putative DNA-binding domain in the NUCKS protein," Archives of Biochemistry and Biophysics, vol. 407, no. 2, pp. 168-175, 2002.

[6] J. R. Wiśniewski, A. Zougman, S. Krüger et al., "Constitutive and dynamic phosphorylation and acetylation sites on NUCKS, a hypermodified nuclear protein, studied by quantitative proteomics," Proteins: Structure, Function, and Genetics, vol. 73, no. 3, pp. 710-718, 2008.

[7] C. Wiese, E. Dray, T. Groesser et al., "Promotion of Homologous Recombination and Genomic Stability by RAD51AP1 via RAD51 Recombinase Enhancement," Molecular Cell, vol. 28, no. 3, pp. 482-490, 2007.

[8] E. Dray, M. H. Dunlop, L. Kauppi et al., "Molecular basis for enhancement of the meiotic DMC1 recombinase by RAD51 associated protein 1 (RAD51AP1)," Proceedings of the National Acadamy of Sciences of the United States of America, vol. 108, no. 9, pp. 3560-3565, 2011.

[9] M. H. Dunlop, E. Dray, W. Zhao et al., "RAD51-associated protein 1 (RAD51AP1) interacts with the meiotic recombinase DMC1 through a conserved motif," The Journal of Biological Chemistry, vol. 286, no. 43, pp. 37328-37334, 2011. 
[10] M. H. Dunlop, E. Dray, W. Zhao et al., "Mechanistic insights into RAD51-associated protein 1 (RAD51AP1) action in homologous DNA repair," The Journal of Biological Chemistry, vol. 287, no. 15, pp. 12343-12347, 2012.

[11] S. I. Walaas, A. C. Østvold, and S. G. Laland, "Phosphorylation of P1, a high mobility group-like protein, catalyzed by casein kinase II, protein kinase C, cyclic AMP-dependent protein kinase and calcium/calmodulin-dependent protein kinase II," FEBS Letters, vol. 258, no. 1, pp. 106-108, 1989.

[12] B. Qiu, W. Han, and V. Tergaonkar, "NUCKS: A potential biomarker in cancer and metabolic disease," Clinical Science, vol. 128, no. 10, pp. 715-721, 2015.

[13] M. A. Nalls, N. Pankratz, and C. M. Lill, "Large-scale metaanalysis of genome-wide association data identifies six new risk loci for Parkinson's disease," Nature Genetics, vol. 46, no. 9, pp. 989-993, 2014.

[14] M. A. Nalls, V. Plagnol, and D. G. Hernandez, "Imputation of sequence variants for identification of genetic risks for Parkinson's disease: a meta-analysis of genome-wide association studies," The Lancet, vol. 377, no. 9766, pp. 641-649, 2011.

[15] T. H. Hamza, C. P. Zabetian, A. Tenesa et al., "Common genetic variation in the HLA region is associated with late-onset sporadic Parkinson's disease.," Nature Genetics, vol. 42, no. 9, pp. 781-785, 2010.

[16] Z. Wei, W. Wang, J. Bradfield et al., "Large sample size, wide variant spectrum, and advanced machine-learning technique boost risk prediction for inflammatory bowel disease," American Journal of Human Genetics, vol. 92, no. 6, pp. 1008-1012, 2013.

[17] S. M. Willems, R. Mihaescu, E. J. G. Sijbrands, C. M. Van Duijn, and A. C. J. W. Janssens, "A methodological perspective on genetic risk prediction studies in type 2 diabetes: Recommendations for future research," Current Diabetes Reports, vol. 11, no. 6, pp. 511-518, 2011.

[18] A. C. Morrison, A. Voorman, A. D. Johnson et al., "Wholegenome sequence-based analysis of high-density lipoprotein cholesterol," Nature Genetics, vol. 45, no. 8, pp. 899-901, 2013.

[19] N. Eriksson, G. M. Benton, C. B. Do et al., "Genetic variants associated with breast size also influence breast cancer risk," BMC Medical Genetics, vol. 13, article 53, 2012.

[20] S. Ripatti, E. Tikkanen, M. Orho-Melander et al., "A multilocus genetic risk score for coronary heart disease: case-control and prospective cohort analyses," The Lancet, vol. 376, no. 9750, pp. 1393-1400, 2010.

[21] J. Simón-Sánchez, C. Schulte, and J. M. Bras, "Genome-wide association study reveals genetic risk underlying Parkinson's disease," Nature Genetics, vol. 41, no. 12, pp. 1308-1312, 2009.

[22] W. Satake, Y. Nakabayashi, I. Mizuta et al., "Genome-wide association study identifies common variants at four loci as genetic risk factors for Parkinson's disease," Nature Genetics, vol. 41, no. 12, pp. 1303-1307, 2009.

[23] X. Liu, R. Cheng, M. Verbitsky et al., "Genome-Wide association study identifies candidate genes for Parkinson's disease in an Ashkenazi Jewish population," BMC Medical Genetics, vol. 12, article 104, 2011.

[24] V. Vacic, L. J. Ozelius, L. N. Clark et al., "Genome-wide mapping of IBD segments in an Ashkenazi PD cohort identifies associated haplotypes," Human Molecular Genetics, vol. 23, no. 17, Article ID ddu158, pp. 4693-4702, 2014.

[25] Z. Lv, W. Tian, Q. Ma, Y. Hao, and Y. Yang, "Interactions between four gene polymorphisms and their association with patients with Parkinson's disease in a Chinese Han population," International Journal of Neuroscience, vol. 127, no. 12, pp. 11541160, 2017.

[26] L. Pihlstrøm, A. Rengmark, K. A. Bjørnarå et al., "Fine mapping and resequencing of the PARK16 locus in Parkinson's disease," Journal of Human Genetics, vol. 60, no. 7, pp. 357-362, 2015.

[27] C. M. Lill, J. T. Roehr, M. B. McQueen et al., "Comprehensive research synopsis and systematic meta-analyses in Parkinson's disease genetics: The PDgene database," PLoS Genetics, vol. 8, no. 3, Article ID e1002548, 2012.

[28] H. Li, Y.-Y. Teo, and E.-K. Tan, "Patterns of linkage disequilibrium at PARK16 may explain variances in genetic association studies," Movement Disorders, vol. 30, no. 10, pp. 1335-1342, 2015.

[29] L. Wang, L. Cheng, Z.-J. Lu, X.-Y. Sun, J.-Y. Li, and R. Peng, "Association of three candidate genetic variants in RAB7L1/NUCKS1, MCCC1 and STK39 with sporadic Parkinson's disease in Han Chinese," Journal of Neural Transmission, vol. 123, no. 4, pp. 425-430, 2016.

[30] G. R. Fries, J. Quevedo, C. P. Zeni et al., "Integrated transcriptome and methylome analysis in youth at high risk for bipolar disorder: a preliminary analysis," Translational Psychiatry, vol. 7, no. 3, article e1059, 2017.

[31] J. R. Perry, F. Day, C. E. Elks et al., "Parent-of-origin-specific allelic associations among 106 genomic loci for age at menarche," Nature, vol. 514, no. 7520, pp. 92-97, 2014.

[32] L. Xu, C. Xia, W. Sun, X. Qin, Y. Qiu, and Z. Zhu, "Genetic Polymorphism of NUCKS1 Is Associated with the Susceptibility of Adolescent Idiopathic Scoliosis," The Spine Journal, vol. 42, no. 21, pp. 1629-1634, 2017.

[33] D. L. Cousminer, D. J. Berry, N. J. Timpson et al., "Genomewide association and longitudinal analyses reveal genetic loci linking pubertal height growth, pubertal timing and childhood adiposity," Human Molecular Genetics, vol. 22, no. 13, pp. 27352747, 2013.

[34] L. Gu, B. Xia, L. Zhong et al., "NUCKS1 overexpression is a novel biomarker for recurrence-free survival in cervical squamous cell carcinoma," Tumor Biology, vol. 35, no. 8, pp. 7831-7836, 2014.

[35] T. Liu, S. Tan, Y. Xu et al., "Increased NUCKS expression is a risk factor for poor prognosis and recurrence in endometrial cancer," American Journal of Cancer Research, vol. 5, no. 12, pp. 3659-3667, 2015.

[36] A. Kikuchi, T. Ishikawa, K. Mogushi et al., "Identification of NUCKS1 as a colorectal cancer prognostic marker through integrated expression and copy number analysis," International Journal of Cancer, vol. 132, no. 10, pp. 2295-2302, 2013.

[37] M. Yang, X. Wang, Q. Zhao et al., "Combined evaluation of the expression of NUCKS and Ki-67 proteins as independent prognostic factors for patients with gastric adenocarcinoma," Tumor Biology, vol. 35, no. 8, pp. 7505-7512, 2014.

[38] J. Gerdes, H. Lemke, and H. Baisch, "Cell cycle analysis of a cell proliferation associated human nuclear antigen defined by the monoclonal antibody Ki-67,' The Journal of Immunology, vol. 133 , no. 4, pp. 1710-1715, 1984 .

[39] K. Zduniak, S. Agrawal, K. Symonowicz, K. Jurczyszyn, and P. Ziółkowski, "The comparison of nuclear ubiquitous casein and cyclin-dependent kinases substrate (NUCKS) with Ki67 proliferation marker expression in common skin tumors," Polish Journal of Pathology, vol. 65, no. 1, pp. 48-54, 2014.

[40] K. Symonowicz, K. Duś-Szachniewicz, M. Woźniak et al., "Immunohistochemical study of nuclear ubiquitous casein 
and cyclin-dependent kinase substrate 1 in invasive breast carcinoma of no special type," Experimental and Therapeutic Medicine, vol. 8, no. 4, pp. 1039-1046, 2014.

[41] P. Ziókowski, E. Gamian, B. Osiecka, A. Zougman, and J. R. Wiśniewski, "Immunohistochemical and proteomic evaluation of nuclear ubiquitous casein and cyclin-dependent kinases substrate in invasive ductal carcinoma of the breast," Journal of Biomedicine and Biotechnology, vol. 2009, Article ID 919645, 2009.

[42] N. A. Soliman, D. H. Zineldeen, and O. H. El-Khadrawy, "Effect of NUCKS-1 overexpression on cytokine profiling in obese women with breast cancer," Asian Pacific Journal of Cancer Prevention, vol. 15, no. 2, pp. 837-845, 2014.

[43] R. Liu, X. Wang, G. Y. Chen et al., "The prognostic role of a gene signature from tumorigenic breast-cancer cells," The New England Journal of Medicine, vol. 356, no. 3, pp. 217-226, 2007.

[44] J. Y. Cheong, Y. B. Kim, J. H. Woo et al., "Identification of NUCKS1 as a putative oncogene and immunodiagnostic marker of hepatocellular carcinoma," Gene, vol. 584, no. 1, pp. 47-53, 2016.

[45] H. Shen, L. Wang, X. Ge et al., "MicroRNA-137 inhibits tumor growth and sensitizes chemosensitivity to paclitaxel and cisplatin in lung cancer," Oncotarget , vol. 7, no. 15, pp. 20728 20742, 2016.

[46] S. A. El-Aarag, A. Mahmoud, M. H. Hashem, H. Abd Elkader, A. E. Hemeida, and M. ElHefnawi, "In silico identification of potential key regulatory factors in smoking-induced lung cancer," BMC Medical Genomics, vol. 10, no. 1, pp. 1-11, 2017.

[47] Y. Yue, S. G. Leung, Y. Liu et al., "Nucks1 synergizes with Trp53 to promote radiation lymphomagenesis in mice," Oncotarget, vol. 7, no. 38, pp. 61874-61889, 2016.

[48] H.-Y. Kim, B.-S. Choi, S. S. Kim, T.-Y. Roh, J. Park, and C.H. Yoon, "NUCKS1, a novel Tat coactivator, plays a crucial role in HIV-1 replication by increasing Tat-mediated viral transcription on the HIV-1 LTR promoter," Retrovirology, vol. 11, no. 1, article 67, 2014.

[49] L. M. Sargent, M. X. Ensell, A.-C. Ostvold et al., "Chromosomal changes in high- and low-invasive mouse lung adenocarcinoma cell strains derived from early passage mouse lung adenocarcinoma cell strains," Toxicology and Applied Pharmacology, vol. 233, no. 1, pp. 81-91, 2008.

[50] A. C. Parplys, W. Zhao, N. Sharma et al., "NUCKS1 is a novel RAD51AP1 paralog important for homologous recombination and genome stability," Nucleic Acids Research, vol. 43, no. 20, pp. 9817-9834, 2015.

[51] A. A. Alizadeh, S. P. Bohen, C. Lossos et al., "Expression profiles of adult T-cell leukemialymphoma and associations with clinical responses to zidovudine and interferon $\alpha$, Leukemia \& Lymphoma, vol. 51, no. 7, pp. 1200-1216, 2010.

[52] M. A. Bellinger, J. S. Bean, M. A. Rader et al., "Concordant changes of plasma and kidney microRNA in the early stages of acute kidney injury: time course in a mouse model of bilateral renal ischemia-reperfusion," PLoS ONE, vol. 9, no. 4, Article ID e93297, 2014.

[53] M.-W. Poon, D. Jiang, P. Qin et al., "Inhibition of NUCKS Facilitates Corneal Recovery Following Alkali Burn," Scientific Reports, vol. 7, Article ID 41224, 2017.

[54] B. Qiu, X. Shi, E. Wong et al., "NUCKS Is a Positive Transcriptional Regulator of Insulin Signaling," Cell Reports, vol. 7, no. 6, pp. 1876-1886, 2014.
[55] B. Qiu, X. Shi, Q. Zhou et al., "Hypothalamic NUCKS regulates peripheral glucose homoeostasis," Biochemical Journal, vol. 469, no. 3, pp. 391-398, 2015.

[56] J. Savitz, M. B. Frank, T. Victor et al., "Inflammation and neurological disease-related genes are differentially expressed in depressed patients with mood disorders and correlate with morphometric and functional imaging abnormalities," Brain, Behavior, and Immunity, vol. 31, pp. 161-171, 2013.

[57] F. Akbari Moqadam, E. A. M. Lange-Turenhout, I. M. Ariës, R. Pieters, and M. L. den Boer, "MiR-125b, miR-100 and miR-99a co-regulate vincristine resistance in childhood acute lymphoblastic leukemia," Leukemia Research, vol. 37, no. 10, pp. 1315-1321, 2013.

[58] H.-L. Ang and V. Tergaonkar, "Notch and NF $\kappa$ B signaling pathways: Do they collaborate in normal vertebrate brain development and function?" BioEssays, vol. 29, no. 10, pp. 10391047, 2007.

[59] G. Cildir, S. C. Akincilar, and V. Tergaonkar, "Chronic adipose tissue inflammation: all immune cells on the stage," Trends in Molecular Medicine, vol. 19, no. 8, pp. 487-500, 2013.

[60] C. V. Dang, "MYC on the path to cancer," Cell, vol. 149, no. 1, pp. 22-35, 2012.

[61] V. Tergaonkar, "NFkappaB pathway: a good signaling paradigm and therapeutic target," The International Journal of Biochemistry \& Cell Biology, vol. 38, no. 10, pp. 1647-1653, 2006.

[62] C. L. Clelland, L. L. Read, L. J. Panek, R. H. Nadrich, C. Bancroft, and J. D. Clelland, "Utilization of Never-Medicated Bipolar Disorder Patients towards Development and Validation of a Peripheral Biomarker Profile," PLoS ONE, vol. 8, no. 6, Article ID e69082, 2013.

[63] M. B. Kastan and J. Bartek, "Cell-cycle checkpoints and cancer," Nature, vol. 432, no. 7015, pp. 316-323, 2004.

[64] S. Matsuoka, B. A. Ballif, A. Smogorzewska et al., "ATM and ATR substrate analysis reveals extensive protein networks responsive to DNA damage," Science, vol. 316, no. 5828, pp. 1160-1166, 2007.

[65] L. D. Ward and M. Kellis, "HaploReg: a resource for exploring chromatin states, conservation, and regulatory motif alterations within sets of genetically linked variants," Nucleic Acids Research, vol. 40, no. 1, pp. D930-D934, 2012. 


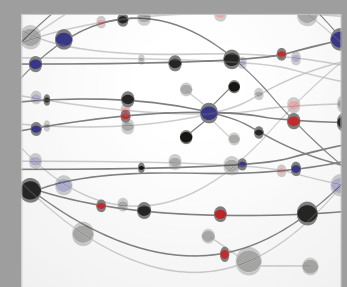

The Scientific World Journal
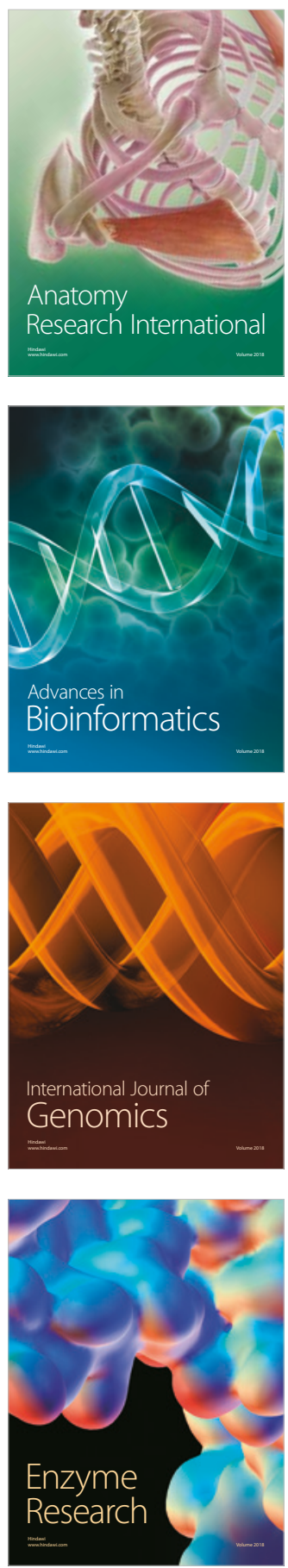
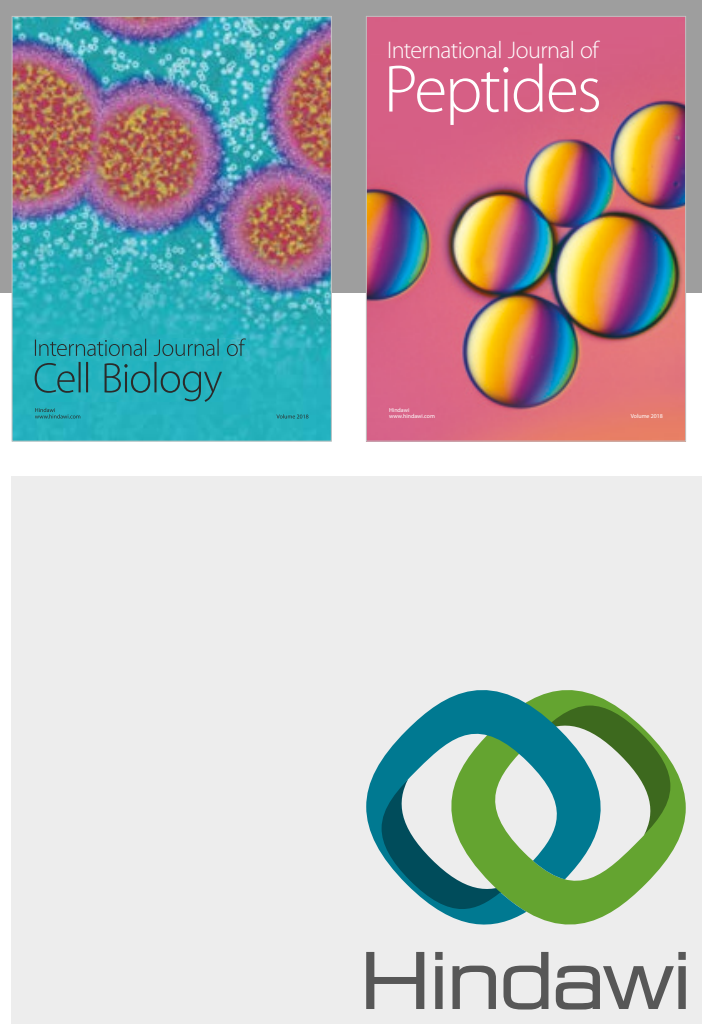

Submit your manuscripts at

www.hindawi.com
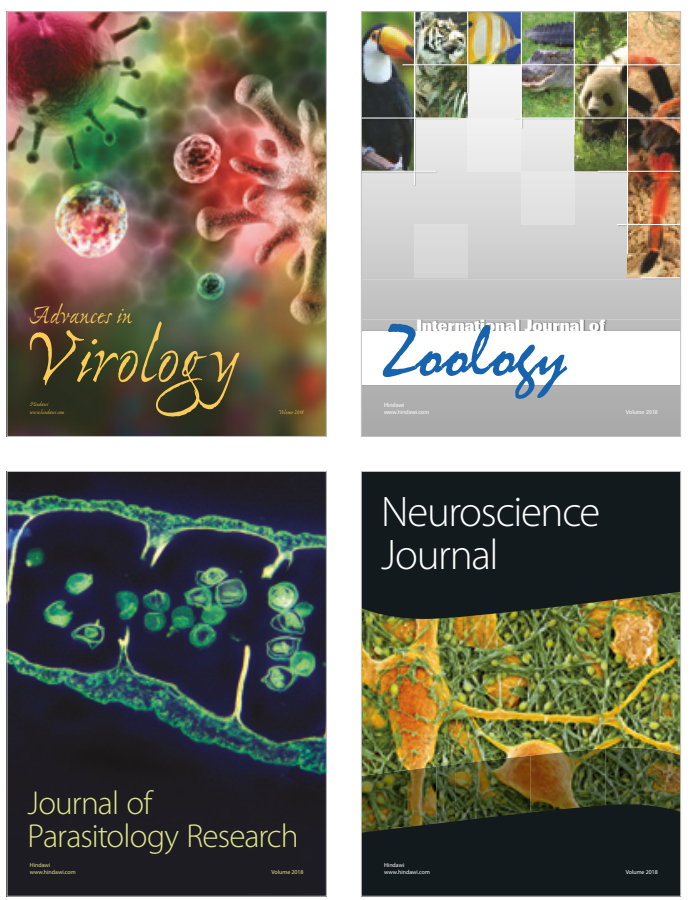
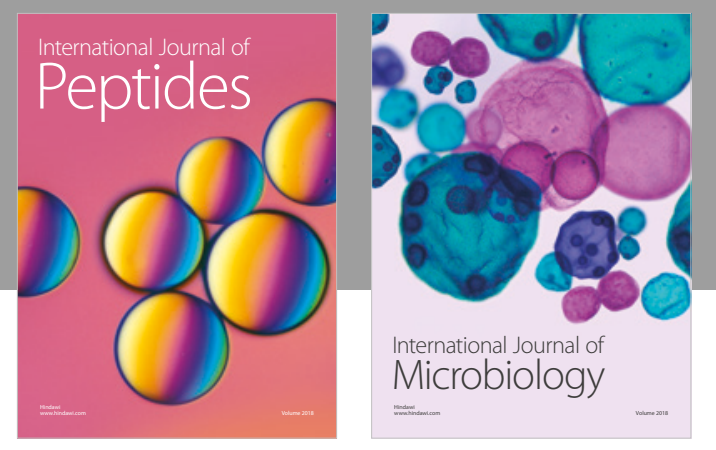

nternational Journal of Microbiology
Journal of
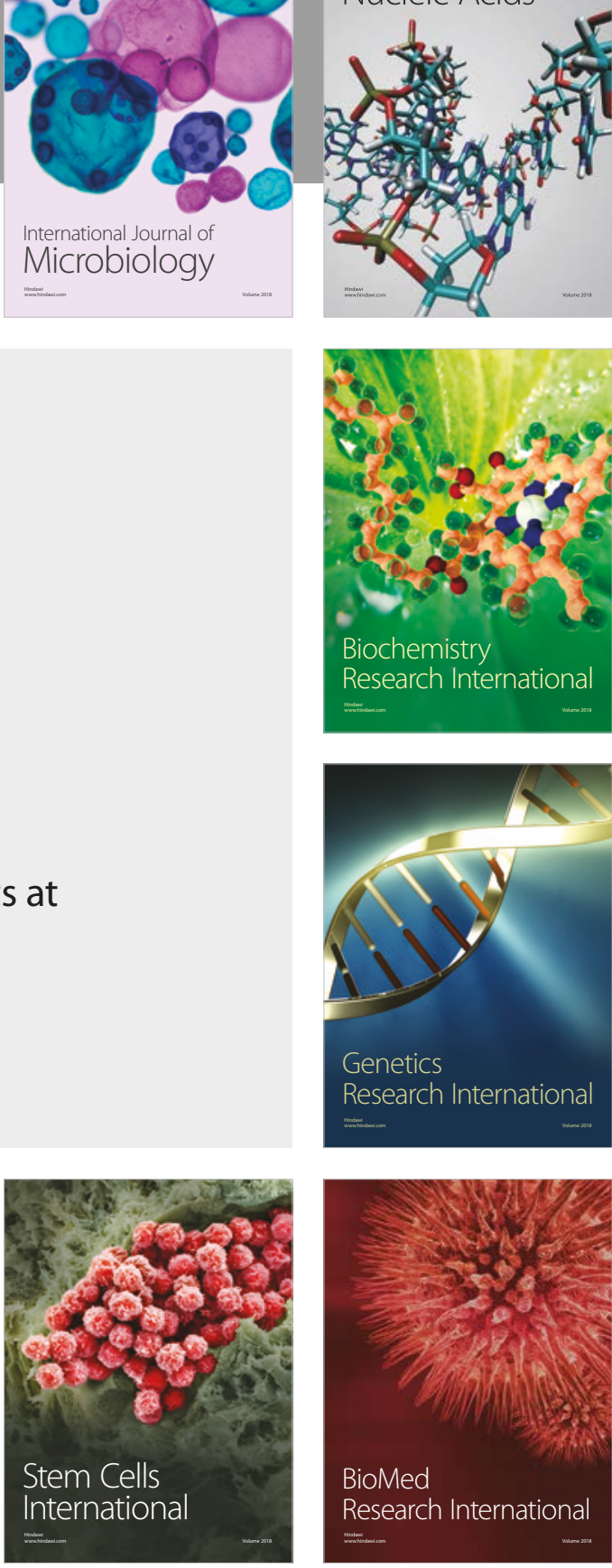
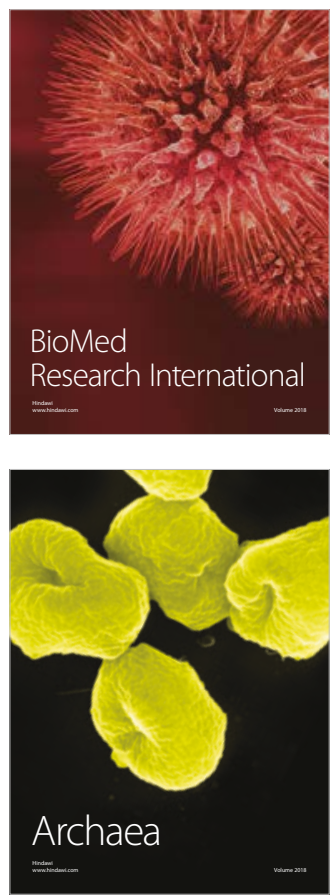